\title{
ELEMENTOS HISTÓRICOS DA INTERVENÇÃO DO ESTADO E A RETOMADA DAS POLÍTICAS INDUSTRIAIS NO BRASIL
}

\author{
Wellington Pereira*
}

RESUMO: Este artigo tem o objetivo de discutir a importância da intervenção do Estado na promoção de interesses econômicos com vistas ao desenvolvimento de longo prazo das nações. Diversos países que hoje são classificados como desenvolvidos se utilizaram de políticas intervencionistas e protecionistas para promoverem seu desenvolvimento ao longo do tempo. Desta forma, o artigo apresenta os elementos que caracterizam o Estado e que dão o respaldo necessário para a sua intervenção na economia. Contudo, há interesses diversos que determinam a posição ocupada pelo Estado quando se decide a favor ou contra à sua intervenção na economia. Para demonstrar que essa prática já foi muito recorrente, faz-se um breve resgate histórico sobre a utilização de políticas públicas como estratégia de desenvolvimento por diversos países. Por fim, discute-se sobre a retomada da utilização de políticas industriais, por parte do Estado brasileiro, como forma de fomentar o desenvolvimento de longo prazo no país.

PALAVRAS-CHAVE: Intervenção econômica; Políticas industriais; Desenvolvimento de longo prazo.

\section{HISTORICAL FACTS ON STATE INTERVENTION AND THE RE- EMERGENCE OF INDUSTRIAL POLICIES IN BRAZIL}

\begin{abstract}
The importance of State intervention in the promotion of economic interests for the long term development of nations is discussed. Several developed countries have employed interventionist and protectionist policies to enhance development throughout time. Factors that characterize the State and give the required support for its intervention in the economy are provided. There are, however, different interests that determine the State's stance when it decides in favor of or contrary to intervention in the economy. A brief historical review is given on the use of political policies as development strategies by several countries. The re-emergence of industrial policies by the Brazilian State as a form of enhancing the country's long term development is discussed.
\end{abstract}

KEY WORDS: Economic intervention; Industrial policies; Long term development. 


\section{INTRODUÇÃO}

Este artigo tem o objetivo de discutir a importância da intervenção do Estado na promoção de interesses econômicos com vistas ao desenvolvimento dos países. É fato que diversos países, hoje desenvolvidos, se utilizaram de políticas intervencionistas e protecionistas para promoverem seu desenvolvimento.

Assim, resgata-se a discussão sobre intervenção do Estado, exemplos históricos desse tipo de comportamento adotados por outros países e a retomada de estratégias adotadas pelo Brasil, por meio de políticas industriais que estimulam e apoiam setores produtivos, considerados essenciais para o desenvolvimento de longo prazo.

O texto está organizado em quatro seções, além dessa breve introdução e dos comentários finais. Na segunda seção se apresentam alguns elementos que ajudam a caracterizar o Estado e o respaldo que sedimenta sua intervenção na economia. Na terceira seção, discute-se o jogo de interesses que contorna a posição ocupada pelo Estado quando ocorre (ou não) a intervenção. A quarta seção resgata, historicamente, a importância da utilização de políticas públicas como estratégia de desenvolvimento utilizada por diversos países. A quinta seção indica a retomada da aceitação da utilização de políticas industriais, por parte do Estado, como forma de fomentar o desenvolvimento de longo prazo no Brasil.

\section{O ESTADO E O ARCABOUÇOJURÍDICO PARAA INTERVENÇÃO ECONÔMICA}

A ideia de regulação estatal vem desde a configuração do modelo "westfaliano"2 de Estado, quando se inicia a dissociação do Estado perante a sociedade civil, de modo que o primeiro passa a ser entidade estranha a quem foram conferidos todos os poderes para a defesa e guarda do interesse público.

2 Com a paz de Westfália de 1648 se consolidou a tendência europeia de territorialização da política, o que é pioneiro no ato de acatar noções e princípios de soberania estatal e Estado-nação. Assim, as relações políticas passavam a ser delimitadas por territórios geográficos, e as relações externas passavam a ser entre Estados soberanos e não mais entre pessoas, nem mediadas por laços religiosos ou de sangue. 
É assim, dentro desse contexto, que se desenvolvem as relações econômicas e a sua regulação pelo Estado.

A análise da evolução dos modelos de atuação do Estado aponta para a passagem de um modelo moderno para outro pós-moderno. No âmbito do modelo moderno houve a passagem do que seria o modelo liberal (séculos XVIII e XIX) para o modelo do bem-estar social (fins do século XIX e início do século XX) e o modelo socialista (século XX). "Nesses três modelos históricos considerados, o papel do Estado na economia variou da extrema abstenção (Liberalismo) à extrema intervenção (Socialismo real), com inúmeras variantes históricas intermediárias entre as duas posturas radicais" (MOREIRA NETO, 2003, p. 101).

Mas é nessa passagem do modelo liberal para o de bem-estar social que são criadas ações ativas e instituições que marcariam o contraste com o laissez faire, laissez passer predominante, até então: a diferenciação política, a política de obras públicas, as empresas estatais e a previdência social.

O predomínio do Estado Liberal se dá até a década de 1930, com a crise internacional, abrindo passagem para o Estado do bem-estar social que chega ao final da década de 1960 enfraquecido. Conforme aponta Moreira Neto (2003), é com essa dupla falência de modelos, ao longo do século XX, que se abre caminho para a transição para um Estado pós-moderno, no qual se verifica a explosão das comunicações, a ineficiência das prestações estatais, o custo excessivo da máquina do Estado moderno, a democratização, a globalização e a reavaliação da pessoa humana e emergência dos seus direitos fundamentais.

A passagem para esse modelo pós-moderno do Estado foi marcada pela pregação de duas ideias: a competição e a eficiência. Essa competição associada à eficiência passa a não estar associada diretamente a Estados, mas sim a sociedades, que passam a demandar esse tipo de postura mais fortemente. Assim, nesse novo contexto o Estado passa a ter que desempenhar funções essenciais para que a competição e a eficiência possam ocorrer efetivamente. Ele deve ser regulador do mercado, alocador de recursos, parceiro econômico e fomentador econômico (MOREIRA NETO, 2003).

No bojo dessa discussão sobre o modelo de ação do Estado, tem-se o que ficou conhecido como American style regulation, o qual trouxe para a análise jurídica a interpretação de que o Estado intervém somente quando precisa sanar 
possíveis falhas do mercado, de modo a ser o menos intrusivo possível (MOREIRA, 2005). Apesar de esse tipo de abordagem ser atribuída aos EUA, ela também teve presença forte na Europa, a partir da defesa do liberalismo econômico, pregado pela Grã-Bretanha, sobretudo no século XIX. É fato que mesmo tendo-se uma influência forte do American style regulation, os EUA sempre exerceram protecionismo em várias atividades econômicas, em diversos momentos do tempo, conforme se discutirá mais adiante.

Assim, o Estado teria um escopo específico ao querer atuar no mercado, devido a falhas que o mercado sozinho não sanaria. "O objetivo da atuação estatal é, assim, claro e delimitado: eliminar [ou reduzir] essas falhas, para que se tenha como resultado o melhor grau de eficiência alocativa possível" (FORGIONI, 2005, p. 426).

Streck e Morais (2001) são críticos ao dizer que o intervencionismo estatal, que deveria realizar a função social do Estado, somente serviu para a acumulação de capital e renda para as elites brasileiras. Assim, o "Estado intervencionista não é uma concessão do capital, mas a única forma de a sociedade capitalista se preservar, necessariamente mediante empenho na promoção da diminuição das desigualdades socioeconômicas" (STRECK e MORAIS, 2001, p. 73-74).

Baseando-se nesse contexto que passou a delimitar cada vez mais a atuação do Estado a favor de interesses sociais amplos e não restritos a grupos socialmente superiores, Streck e Morais (2001) reafirmam a necessidade de um Estado e instituições nacionais fortes para garantir os direitos num contexto hostil propiciado pela globalização neoliberal. "É evidente, pois, que em países como o Brasil, em que o Estado social não existiu, o agente principal de toda política deve ser o Estado" (STRECK e MORAIS, 2001, p. 78).

E toda a postura neoliberal e defensora de um desmonte do Estado está na contramão do ordenamento constitucional brasileiro, o qual aponta, segundo Streck e Morais (2001, p. 79), "para um Estado forte, intervencionista e regulador".

A intervenção do Estado na ordem econômica está assegurada em todas as Constituições que o Brasil teve, tal como os direitos dos agentes econômicos privados. Assim, isso teria contribuído para que os governos tivessem tendências mais intervencionistas e produtivas. Pode-se considerar a intervenção do Estado na economia como uma ação ampla, em que regulação e intervenção podem ser verificadas. Assim, o Estado seria um terceiro estranho que surge e pode alterar 
as condutas e perspectivas dos agentes econômicos (MOREIRA, 2005). Assim, ao intervir na economia, o Estado pode afetar e alterar o comportamento econômico "espontâneo" dos agentes privados, de modo a satisfazer algum interesse público.

O fato é que a intervenção estatal na economia não pode visar lucros ou ganhos diversos para agentes econômicos isolados. Assim, a intervenção do Estado produzirá fatos econômicos, o que fará com que os agentes particulares alterem seu comportamento e se reposicionem nos mercados, atingindo seus interesses econômicos.

A intervenção estatal pode se dar de diversas maneiras, como investimentos públicos para instalação de unidade produtiva ou criar novas normas de estímulos promocionais para que as empresas assim o façam. E uma das principais características da intervenção e dos métodos jurídicos utilizados pelo Estado é a redução da coercibilidade, ou seja, o Estado precisa não criar constrangimentos. Assim, os agentes privados podem estabelecer seus comportamentos de modo a alcançar resultados positivos e não desestimulantes.

Sobre os limites jurídicos que o Estado precisa se submeter, Moreira (2005) diz que a própria Constituição coloca as regras jurídicas e padrões econômicos do mercado a que o Estado precisa seguir.

O Estado como impulsionador de iniciativas individuais ou conjuntas, públicas ou privadas, financeiras ou não-financeiras, educativas e técnicas, etc. vistas a partir da possibilidade de implementação de políticas públicas estão, inclusive, registradas como obrigações em constituições contemporâneas, como no caso da brasileira. E é com o foco nessas possibilidades de intervenção do Estado em vista a propiciar resultados positivos para a sociedade, especificamente por meio do fomento econômico, que este texto se desdobrará na sequência.

\section{O ESTADO E O JOGO DE INTERESSES NA CONDUÇÃO DA ECONOMIA}

O Estado pode ser compreendido a partir de várias possibilidades de interpretação, pois dá margem para aplicações diferenciadas a partir das constatações assumidas pelas diferentes linhas teóricas. É muito comum que haja confusões sobre 
a definição de Estado em relação à figura do governo, de estado-nação, país, como também de regimes políticos e econômicos. No que se refere a este último caso, as abordagens econômicas historicamente se referiram à Estados Liberais, Capitalistas, Socialistas, etc., ou seja, liga-se a figura do Estado a um tipo de 'comportamento econômico'.

Segundo Bresser-Pereira (1995) é importante que se diferencie a sociedade civil, que é constituída por classes sociais e grupos, do Estado o qual é interpretado como uma estrutura organizacional e política. Nesse sentido, é importante considerar o Estado como "fruto de um contrato social ou de um pacto político, que garante legitimidade ao governo" (BRESSER-PEREIRA, 1995, p. 87).

Um dado fundamental a ser registrado é que são alguns grupos da sociedade civil, aqueles que possuem maior poder político perante o Estado, ou seja, serão aqueles que conseguirão acessar a 'estrutura estatal' de forma diferenciada. Esse tipo de 'inserção' fica evidente na colocação abaixo:

O Estado é, assim, um sistema de poder organizado que se relaciona dialeticamente com um outro sistema de poder - a sociedade civil cujo poder é difuso mas efetivo. A sociedade civil pode ser entendida como a forma através da qual as classes dominantes se organizam fora do Estado para controlá-lo e pô-lo a seu serviço. A sociedade civil não deve ser confundida portanto com a população ou com o povo. O povo pode ser considerado como sendo o conjunto dos cidadãos detentores dos mesmos direitos; a sociedade civil é constituída pelos cidadãos organizados e classificados segundo o poder dos grupos ou associações a que pertencem" (BRESSER-PEREIRA, 1995, p. 92).

É necessário não ignorar que o Estado é uma estrutura fundamental para que o sistema capitalista possa se manter em funcionamento. E foi o Estado o próprio 'promotor' do mercado e das regulamentações que surgem com ele. No entanto, ao longo do século XIX, a ideologia liberal e de livre comércio pregada pela Grã-Bretanha induz a que o mercado vá 'liberando-se de suas amarras'. A defesa do socialismo utópico, por exemplo, foi uma reação da sociedade que não queria mercados autorregulados (POLANYI, 2000).

Não há capitalismo, nem mercado capitalista, sem um Estado que 
o regulamente e coordene, não apenas criando as condições gerais para a produção capitalista, através da instituição do sistema legal com poder de coerção e de uma moeda nacional, mas também através de uma série de ações na área econômica, social e meio ambiente (BRESSER-PEREIRA, 1995 p. 85)

Dada essa constatação da relação direta do Estado com o sistema capitalista, é interessante notar a contradição vista por meio da atuação do Estado (que regula para manter o funcionamento do sistema) versus a legitimação dada a ele, pela sociedade civil no seu agregado, para promover o bem-estar social. BresserPereira (1995) aponta que o Estado não pode ser totalmente capitalista porque está estruturado sobre uma organização burocrática e não em relações mercantis, apesar de o Estado ser essencial para o sistema capitalista.

É após a Segunda Guerra Mundial, sobretudo, que ocorre o início de debates teóricos entre Policy makers no que se refere à economia do desenvolvimento econômico e social. O período seguinte ficou conhecido como a era dourada, quando o Estado foi agente fundamental no processo de recuperação econômica no mundo, inclusive atuando como 'empresário', como ocorreu no caso brasileiro, por exemplo.

Mas nem sempre as crenças recaiam nesse tipo de postura adotada pelo Estado. Conforme já se citou anteriormente, o American style regulation sempre demonstrou ceticismo em relação à intervenção do Estado na promoção econômica.

Segundo Boyer (1999), os exemplos dos regimes soviéticos ou das economias com fortes intervenções do Estado eram a prova máxima da incapacidade do Estado em gerir uma complexidade crescente de informações características de economias mais modernas, de modo que somente a descentralização dessa gestão no mercado tornaria possível a boa articulação dos agentes em prol do desenvolvimento econômico e social. Isso resume fortemente o debate que pode ser colocado entre dois grandes teóricos com posições opostas sobre o assunto: Friedrich Hayek e Karl Polanyi.

Quadro 1. Rumo a uma concepção equilibrada das relações Estado/mercado 


\begin{tabular}{|c|c|}
\hline A crise do Consenso de Washington & \begin{tabular}{|c|}
$\begin{array}{c}\text { Estado e mercado: complementaridade } \\
\text { no seio de ordenamentos institucionais } \\
\text { variados }\end{array}$ \\
\end{tabular} \\
\hline $\begin{array}{l}\text { 1. Instabilidade ou crises políticas } \\
\text { 2. Desemprego/crescimento das } \\
\text { desigualdades, consequência dos } \\
\text { ajustamentos de mercado } \\
\text { 3. Sub-investimento nas infraestruturas } \\
\text { coletivas } \\
\text { 4. Forte dependência em relação ao } \\
\text { cenário internacional } \\
\text { 5. Desestabilização dos regmes de } \\
\text { crescimento pelos movimentos de capitais }\end{array}$ & $\begin{array}{l}\text { 1. Re-legitimação do Estado: promotor do } \\
\text { crescimento e da justiça social } \\
\text { 2. Ao mercado a coordenação das } \\
\text { decisões do dia-a-dia, ao Estado as } \\
\text { decisões estratégicas } \\
\text { 3. O setor público garante a coesão social } \\
\text { e as infraestruturas coletivas } \\
\text { 4. Manutenção de um equilíbio entre } \\
\text { necessidades domésticas e } \\
\text { competitividade externa } \\
\text { 5. Abertura internacional diferenciada em } \\
\text { função de objetivos nacionais e de áreas }\end{array}$ \\
\hline
\end{tabular}

Fim dos anos 90

Início do século XXI

Fonte: (BOYER,1999, p. 18)

O quadro1 indica como se dá a evolução da discussão sobre o papel do Estado no que tange à economia a partir do contexto do Consenso de Washington. É fato que muitos órgãos internacionais passaram a reconhecer o papel central do Estado na consolidação de instituições necessárias ao 'florescimento do mercado' (BOYER, 1999).

No entanto, há uma crescente adesão ao que tem sido pregado pelos autores defensores do progresso técnico no que se refere ao papel que a inovação pode gerar para o desenvolvimento de longo prazo dos países. Nisso se incluem, necessariamente, a participação do Estado, por meio de políticas públicas, como fomentador de atividades portadoras de progresso e que possibilitarão a geração de externalidades positivas para o encadeamento produtivo de uma localidade, região e ou de um país. Assim, conforme aponta Boyer (1999, p. 05), o Estado não somente corrige "lacunas do mercado, mas institui vários deles [mercados], graças à promulgação de regras extremamente precisas que garantem a viabilidade".

Apesar da retomada da defesa do Estado liberalizante a partir dos anos 1980, ficou evidente, com as crises desencadeadas a partir de então, a capacidade limitada do mercado em gerir as relações no âmbito de um sistema capitalista avançado. Boyer 
(1999) registra que um excesso de mercado pode prejudicar o desenvolvimento, e que o século XXI tenderá a ser marcado por relações mais equilibradas entre mercado e Estado. No entanto, como bem registra Bresser-Pereira (1995), a ação do Estado sempre será resultado da representação de interesses em conflito, de modo que o Estado jamais será neutro.

\section{A DEFINIÇÃO DE POLÍTICAS COMO ESTRATÉGIA DE DESENVOLVIMENTO}

O debate iniciado em 1949 por Prebisch (2000), quando do lançamento de seu texto inaugural da Comissão Econômica para América Latina e Caribe (CEPAL) ao tratar sobre o problema dos termos de troca prejudiciais para os países dependentes da venda de commodities prevalece até hoje. Em resumo, o argumento defendido era de que os países da América Latina e Caribe, ao ficarem especializados e reféns da venda de produtos básicos, e dependentes da compra de produtos manufaturados advindos de países desenvolvidos, não conseguiriam promover seu desenvolvimento, porque existe uma tendência histórica de deterioração dos preços de produtos básicos, frente aos preços dos itens manufaturados.

Assim, a defesa da CEPAL pela industrialização, por meio de políticas públicas que impulsionassem o desenvolvimento na América Latina e Caribe, foi uma tônica ao longo de diversas décadas, de modo que muitos países procuraram seguir essa recomendação, tal como fez o Brasil por meio de seus grandes planos de desenvolvimento nos anos 1960 e 1970, com o objetivo de substituir importações e reestruturar a capacidade produtiva interna.

\subsection{RESGATE HISTÓRICO DO APOIO ESTATAL AO DESENVOLVIMENTO}

$\mathrm{Na}$ tentativa de discutir a relação da base produtiva dos países com seu tipo de inserção internacional, ou mesmo, de relacionamento com outros países, vale registrar que, conforme apontam Suzigan e Albuquerque (2011), a história mundial permite ver que existe uma espécie de coincidência entre a posição de liderança científica e tecnológica, com a supremacia econômica em diversos momentos do 
tempo. A análise histórica aponta a liderança de diversos centros de poder ao longo do tempo, desde Veneza no século XIV, passando por Amsterdã no século XVII e Londres no século XVIII e XIX, até chegar a Nova Iorque no início do século XX. Esses centros foram, historicamente, polos catalizadores de dinamismo econômico, mas que se amparavam nas dinâmicas em torno de 'patrocínios' culturais, tanto no que se refere à arte, como também no que tange aos avanços científicos (SUZIGAN e ALBUQUERQUE, 2011).

Assume-se que a história possui papel decisivo na explicação da posição que muitos países possuem em relação ao seu status de maior ou menor grau de desenvolvimento. Essa rápida abertura de fundo histórico que demarca a evolução econômica mundial é útil para registrar que, tradicionalmente, a análise do crescimento econômico esteve ancorada no papel dinâmico da indústria nos países desenvolvidos, como também é colocada no centro da discussão dos problemas enfrentados no caso dos países em desenvolvimento, conforme já se apontou anteriormente quando se mencionou o caso da América Latina.

Relacionado à defesa de ações em prol da industrialização, tem-se a discussão sobre os impactos e relações da ciência e tecnologia (C\&T) para com o desenvolvimento. Foi, sobretudo, com a ocorrência das duas guerras mundiais que o tema passou a estar crescentemente presente nas estratégias (políticas e depois econômicas e sociais) dos países.

Por mais que existam elementos históricos que demonstrem preocupações diferenciadas por parte dos países em se utilizar de mecanismos para estimular seu desenvolvimento (CHANG, 2004), é só a partir da segunda metade do século XX que se verifica um crescimento e adensamento da produção e sistematização de trabalhos acadêmicos mais preocupados em estabelecer relação entre a ciência, a tecnologia e a inovação e suas implicações para com a sociedade, inclusive no que tange à utilização de políticas públicas para tal propósito.

Em teoria econômica, foi somente em 1956 que Robert Solow ${ }^{3}$ publicou o que viria a ser considerado como um trabalho científico seminal nesse debate sobre o impacto da tão desejada inovação em prol do crescimento econômico. Ao tentar explicar o crescimento econômico dos EUA de longo prazo, Solow constatou que

\footnotetext{
Para maiores detalhes, sugere-se a leitura de SOLOW, R. A Contribution to the Theory of Economic Growth.
} The Quarterly Journal of Economics, Vol. 70, No. 1. (Feb., 1956), pp. 65-94. 
a maior parte dele (ou o que se chamou de resíduo) não podia ser explicado pela simples acumulação de capital físico (fator que, historicamente, havia marcado os países que se transformaram em potências desde a Revolução Industrial). Assim, a explicação residia no aumento da produtividade total dos fatores de produção. E esse resultado estava diretamente relacionado com a capacidade que havia sido construída e permitia ter, à disposição, máquinas com tecnologias produtivas mais avançadas e acúmulo de conhecimento que se revertia em prol da melhoria dos processos produtivos.

Por mais que muitos desses conceitos hoje pareçam triviais aos olhares contemporâneos, sobretudo quando analisados sob a perspectiva do discurso político, eles foram melhor entendidos (ou aceitos) há muito pouco tempo. Falar-se em 50 anos para se discutir desenvolvimento econômico de longo prazo, é pouco. Mas, é importante registrar que os encaminhamentos (sobretudo pela ótica da política) que ocorreram ao longo dessas últimas décadas foram amparados na ideia de determinismo tecnológico e de neutralidade nos resultados almejados - o que não é verdadeiro, devido ao fato de que inclusive, como já apontado, o Estado não é neutro e suas políticas tendem a seguir uma postura previamente definida.

Ainda que essas ideias tenham se enraizado fortemente na leitura dos processos e na sua aplicação em políticas públicas ao longo do século XX, é importante enfatizar que já no século XVIII, a ideia do Determinismo já havia ganhado amplo respaldo nos EUA, onde Benjamin Franklin e Thomas Jefferson foram alguns de seus grandes defensores.

Para eles, o progresso significava a busca da tecnologia e da ciência, de modo a melhorar a vida das pessoas e gerar prosperidade (SMITH, 1996). Assim, considerava-se que o modelo linear do progresso seria o fio condutor do processo de avanço da nação (desenvolvimento científico gerando desenvolvimento tecnológico que levaria ao desenvolvimento econômico e, consequentemente, ao desenvolvimento social). Mas hoje temos plenas condições e insumos que permitem refutar essa ordem linear de leitura do processo.

Voltando-se um pouco na história, pode-se resgatar a estratégia de desenvolvimento denominada "List mais Smith" (REINERT, 1994, p.09). Essa foi a postura adotada pelos países que se utilizavam de mecanismos de estímulo às 
suas estruturas produtivas locais, numa primeira fase, adotando, inclusive, medidas protecionistas diversas. E, num segundo momento conseguiam atingir uma situação que permitia atuar em um ambiente marcado pelo livre comércio. A primeira fase é uma referência ao teórico Friedrich List que defendeu a proteção e estímulo à indústria nascente na Alemanha (Escola Histórica Alemã). E a segunda refere-se a Adam Smith, defensor do livre comércio após a Inglaterra já ter atingido uma posição de destaque e de pujança nas relações comerciais no século XVIII.

Nesse aspecto, Chang (2004) segue a mesma abordagem analítica proposta por Reinert (1994). E um dos pontos a reforçar é que os países (EUA, Alemanha, Inglaterra, por exemplo) que se utilizaram da estratégia "List mais Smith" proposta por Reinert (1994) sempre priorizaram atividades promotoras (ou, com expectativas) de retornos crescentes, ou onde a inovação (vista como elemento catalisador de transformações e gerador de externalidades positivas) pudesse surgir.

A crítica de Reinert (1996) é apresentada na figura de uma "armadilha dupla" dos países especializados em recursos naturais, ou atividades de retorno decrescente: a pobreza e a piora da situação crescem na medida em que as nações continuam a se especializar em produtos básicos, de acordo com vantagens comparativas tradicionais no comércio internacional.

Suzigan e Albuquerque (2011) concordam com o que já foi apontado por Reinert (1996) ao afirmar que desde o século XV a Europa já buscava a construção do conhecimento e da ciência. Por um lado, muitos países europeus buscavam matériaprima em países colonizados e tinham nesses locais os mercados para os produtos que geravam retornos crescentes para a economia europeia.

Ao falar da trajetória de desenvolvimento de países que também possuíam uma abundância de recursos naturais, mas nem por isso caíram na armadilha dos retornos decrescentes ao longo do tempo, Reinert (1996) e Chang (2004) concordam que países como Austrália, Canadá e EUA foram conscientes da necessidade de construir uma capacidade industrial local, com forte participação do Estado nessa estratégia de desenvolvimento. Tanto Reinert (1996) como Chang (2004) citam diversos exemplos de como os EUA se utilizou de diversos esforços, inclusive protecionistas, para fomentar atividades industriais que propiciam a ocorrência de retornos crescentes.

Feito esse rápido resgate histórico, pode-se perguntar: por que as 
nações que já eram desenvolvidas e industrializadas continuaram a ser mais ricas e industrialmente avançadas? Simplesmente porque além de propiciarem a cumulatividade do capital, elas também foram capazes de acumular conhecimento e utilizá-lo de modo a aumentar seus retornos, mediante um amplo conjunto de estímulos conduzidos pelo Estado, em diferentes momentos do tempo.

\section{A DEFESA DE POLÍTICAS LIBERALIZANTES E A RETOMADA DO ESTADO}

A partir dos anos 1980 começa um período em que a defesa por políticas liberalizantes ganha terreno de forma crescente em praticamente todo o mundo, e não foi diferente na América Latina. Nesse sentido, é um momento em que marca uma perda de presença do Estado na condução e aplicação de políticas efetivas com vistas à promoção do desenvolvimento econômico e social.

A chamada globalização é outro elemento importante no período que contribuiu para esse processo, de modo que a movimentação de capitais e de pessoas passava a ser cada vez mais acelerada. Adicionalmente, a evolução tecnológica é outro fator subjacente a esse processo que contribuiu para a reconfiguração do processo de acumulação capitalista, inclusive com impactos enormes a partir da crescente liberalização financeira. Assim, o capital financeiro é um elemento que passa a definir, inclusive, o caminho que muitas nações adotam no que se refere à organização econômica, em detrimento do papel do Estado. Esse processo é chamado por Chesnais (1996) de mundialização do capital, indicando a superioridade do capital financeiro em detrimento ao produtivo, e que passa a guiar as relações entre os países.

Nos idos dos anos 1970 já se tinham os indicativos das posturas que viriam a ser bravamente defendidas pela Inglaterra, com Margaret Thatcher, e pelos Estados Unidos, com Ronald Reagan. Ambos defendiam a menor intervenção estatal e um aumento da tributação, ou seja, ações de cunho ortodoxo. Com base nesse cenário, o liberalismo econômico passava a ser defendido como a maneira de assegurar as relações de mercado que contribuiriam para o crescimento econômico.

Essa bandeira acabou sendo incorporada eficazmente pelos órgãos 
internacionais (Banco Mundial e FMI), os quais, em resumo, defendiam os interesses dos países de industrialização avançada. Isso afetou diretamente a América Latina no decorrer das décadas de 1980 e 1990, no bojo das crises da dívida e dos surtos inflacionários. Em resumo, o Estado passava a estar submisso aos mandos e desmandos coordenados pelos proprietários do capital financeiro que passavam 'a ter direito' a coordenar e exigir os rumos a serem adotados no âmbito da gerência da economia interna dos países demandantes de capital. Os anos 1980 vão marcar um período em que o modelo de Estado moderno não mais contemplava as relações internas, porque os espaços econômicos e da regulação econômica passavam a estar além das fronteiras nacionais.

No fim dos anos 1980 foi lançado um receituário de medidas que deveriam ser adotadas por esses países, o qual ficou conhecido como "Consenso de Washington". Ele foi elaborado sob 'supervisão' do Banco Mundial e Fundo Monetário Internacional (FMI) e foi exposto como necessidades a serem adotadas pelos países endividados. As ações determinavam maior abertura comercial e de capital financeiro, privatizações e fim de monopólios do Estado na exploração econômica, maior flexibilidade nas relações trabalhistas, redução dos gastos públicos, não intervenção em mercados cambiais e defesa da propriedade intelectual.

Assim, conforme colocam Verissimo et al (2009) esse modelo adotado ‘̀̀ força' pelos países da América Latina estava preocupado como questões puramente macroeconômicas, por meio de políticas recessivas, as quais geraram os piores resultados em relação ao crescimento econômico e, praticamente eliminaram as condições de o Estado implementar políticas industriais.

\subsection{O RESGATE DAS POLÍTICAS INDUSTRIAIS NO BRASIL NO CONTEXTO RECEN- TE}

É somente nos anos 2000 que se torna possível registrar no Brasil, de forma efetiva, a retomada do Estado como agente impulsionador de políticas industriais que visavam promover o desenvolvimento econômico e social de longo prazo. Segundo Furtado e Suzigan (2006) é possível encontrar diversos documentos que foram preparados pela estrutura estatal nas décadas de 1980 e 1990. No entanto, 
com exceção de alguns programas e políticas específicos (por exemplo: reforma e redução programada das tarifas aduaneiras, proteção temporária a algumas indústrias, programas de estímulo à qualidade), não se pode dizer que existiram políticas efetivas para promover a dinâmica da competitividade industrial.

O fato é que esse período recente tornou possível voltar a se falar da utilização de políticas industriais como mecanismos de promoção do desenvolvimento de um país, conduzidos a partir do Estado, como agente indutor do processo de transformação positiva. As justificativas sempre poderão ser buscadas na história, conforme já se apontou rapidamente sobre as experiências de outros países na utilização de mecanismos que geraram estímulos claros para o desenvolvimento produtivo de diversas nações, hoje consideradas desenvolvidas.

Considera-se, assim, que a chegada de Lula à presidência da República do Brasil foi o marco oficial do desbloqueio do debate e da institucionalização efetiva de instrumentos voltados para o planejamento, coordenação e execução de políticas industriais. Isso ocorreu a partir de 31 de março de 2014 quando foi oficialmente lançada, pelo presidente, a Política Industrial, Tecnológica e de Comércio Exterior (que ficou conhecida como PITCE).

As preocupações centrais da política estavam em fomentar: a inovação e desenvolvimento tecnológico; a inserção externa; a modernização industrial; a capacidade e escala produtiva e outras opções estratégicas. Assim, a PITCE procurava buscar "no curto prazo, diminuir as restrições externas do país e, no médio e longo prazo, equacionar o desenvolvimento de atividades-chave, de modo a gerar capacitações que permitam ao Brasil aumentar sua competitividade no cenário internacional" (BRASIL, 2003, p. 09-10).

O ponto forte da nova releitura e adoção de políticas industriais nessa proposta está na incorporação de uma abordagem schumpeteriana. Ou seja, as diretrizes e metas adotadas passam a se preocupar com a formação e acúmulo de competências (dentre elas, a tecnológica) que contribuem para que se tenha uma visão dinâmica do processo de desenvolvimento. Nessa primeira versão da PITCE, o governo optou por fomentar prioritariamente quatro grandes segmentos (semicondutores, softwares, bens de capital, fármacos e medicamentos) devido a eles terem perfis de inserção horizontal na economia e possuírem características 
estratégicas (na abordagem schumpeteriana), tal como está citado a seguir (BRASIL, 2003, p. 16):

a) apresentam dinamismo crescente e sustentável;

b) são responsáveis por parcelas expressivas dos investimentos internacionais em Pesquisa e Desenvolvimento;

c) abrem novas oportunidades de negócios;

d) relacionam-se diretamente com a inovação de processos, produtos e formas de uso;

e) promovem o adensamento do tecido produtivo;

f) são importantes para o futuro do país e apresentam potencial para o desenvolvimento de vantagens comparativas dinâmicas.

É importante registrar que o lançamento da PITCE, depois de quase 25 anos sem Política Industrial, trata-se de um fator positivo. No entanto, como lembram Furtado e Suzigan (2006) não se pode esquecer de que as políticas industriais precisam estar compatibilizadas com a política macroeconômica do momento, tal como estabelecer instrumentos e regulamentos claros, de modo a se coordenar o avanço conjunto de infraestruturas (em ciência, tecnologia e inovação - C,T\&I) para que o alcance dos propósitos apresentados seja viável.

No que se refere ao andamento e sucesso na condução de uma política industrial (PI), Furtado e Suzigan (2006) são críticos ao apontarem que uma PI como estratégia de desenvolvimento deve ser pensada como uma decisão política, daí que um comando político e uma coordenação efetiva, com poderes decisórios, são essenciais para o sucesso da PI.

Ainda, segundo esses autores, o importante na nova formatação da PI é a necessidade de estabelecimento de metas que devem ser mais qualitativas, pensadas na perspectiva schumpeteriana em que devem se destacar o fomento que propicie inovação e desenvolvimento tecnológico, o que tenderá a gerar resultados em qualidade e produtividade.

Até antes desse programa de PI, todas as formas de coordenação voltadas à gestão de PI haviam sido abandonadas. E todas as possíveis tentativas em relação a programas com cunhos para estímulo do desenvolvimento científico e tecnológico eram interrompidos ou sequer existiam, devido às restrições impostas pelo lado do que se buscava com as tentativas de estabilização macroeconômica.

No final dos anos 1990 e início da década de 2000 o país continuava sem PI, e pior, caso houvesse uma decisão política de formular e im- 
plementar uma PI, vários desafios teriam que ser vencidos. Primeiro, seria necessário superar o viés ideológico anti-PI que se cristalizara após anos de predomínio do pensamento econômico neoliberal, que em boa medida se cristalizou - também - em razão do esgotamento dos velhos modelos de intervenção, típicos da fase de substituição de importações (SUZIGAN; FURTADO, 2006, p.173).

Assim, pode-se considerar o lançamento da PITCE como um grande avanço no que se refere, sobretudo, à superação de um viés anti-política industrial nas mentes dos gestores contemporâneos. Para Suzigan e Furtado (2006), a PITCE possuía pontos positivos, tal como as ações sendo definidas a partir de uma crença na inovação, mas também possuíam características negativas, a saber: incompatibilidade entre a PITCE e a política macroeconômica, grande falta de articulação dos instrumentos lançados com as demandas das empresas, precariedades e insuficiências no sistema de ciência, tecnologia e inovação, como também a própria fragilidade na centralidade do comando de uma política industrial. Este último ponto é essencial para o sucesso de uma efetiva PI que possa mitigar incertezas e riscos, de modo que as empresas possam aceitar assumi-los e fazer com a política tenha sucesso.

Como desdobramento da PITCE lançada no início de 2004, foram aprovadas duas leis importantes para fomentar um ambiente mais propício ao avanço da inovação tecnológica no Brasil, de modo a beneficiar a competitividade industrial. A Lei 10.973 de 2 de dezembro de 2004, conhecida como Lei da Inovação Tecnológica, foi aprovada com o objetivo de estimular a criação de ambientes especializados e cooperativos em inovação, além de estimular a participação e o relacionamento entre instituições cientificas, indivíduos e empresas públicas e privadas em projetos voltados à inovação tecnológica (BRASIL, 2004).

Além disso, a Lei 11.196 de 21 de novembro de 2005, apelidada de Lei do Bem, regulamentou a concessão de incentivos fiscais às pessoas jurídicas que demonstrassem realizar investimentos e atividades em pesquisa e desenvolvimento (P\&D) voltados à inovação tecnológica (BRASIL, 2005).

Ainda que muitas críticas tenham surgido após a implementação dessas leis, por parte de gestores e empresários, que apontavam problemas relacionados aos mecanismos de coordenação, que geravam maior burocracia, e àqueles que bloqueavam a obtenção das isenções fiscais pelas empresas, devido a questionamentos 
das áreas fiscalizadoras sobre o caráter efetivo dos investimentos ditos para a inovação tecnológica, é importante reconhecer o avanço que tais leis propiciaram ao Brasil, comparativamente a outros países onde maiores investimentos em P\&D já são recorrentes.

Adicionalmente, é importante destacar que a partir da PITCE foram criados o Conselho Nacional de Desenvolvimento Industrial (CNDI) e a Agência Brasileira de Desenvolvimento Industrial (ABDI) com o propósito de se organizar uma engenharia institucional de modo a articular a relação entre setor público e privado (FERRAZ, 2009). Esse era um ponto considerado crítico pelo grupo de trabalho encarregado de pensar a política industrial do governo Lula. Assim, a necessidade de uma maior coordenação das diversas atividades apresentadas pela PITCE e o devido acompanhamento e avaliação das ações passou a ser uma designação da ABDI (ALMEIDA, 2009).

Após a PITCE, dois outros grandes programas de política industrial foram implementados no Brasil. Em maio de 2008, já no segundo mandato de Lula na presidência da República, foi lançada a Política de Desenvolvimento Produtivo (PDP).

Tratou-se de um reposicionamento em relação à política anterior (a PITCE), de modo que a PDP foi lançada como uma política mais ampla no que se referia ao foco em um maior número de setores econômicos. A PDP apresentou quatro macrometas que visavam acelerar o investimento fixo, estimular a inovação, ampliar a inserção internacional do Brasil e aumentar o número de micro e pequenas empresas exportadoras (ABDI, 2008). Além disso, também possuía metas para programas específicos (ALMEIDA, 2009). Dentre as medidas fiscais adotadas no âmbito da PDP podemos citar a redução de tributos, a equalização de taxas de juros, a simplificação de investimentos, a redução do custo tributário e financeiro sobre investimentos e exportações (ABDI, 2008).

APDP procurou avançar em relação a PITCE no que tange ao estabelecimento de metas quantitativas de forma explícita. Assim, a PDP teve a preocupação de se aprofundar em medidas já propostas na PITCE, mas definindo metas e instrumentos de acompanhamento de forma mais objetiva. Isso contribuiu para, também, sinalizar ao setor privado como estava sendo a gestão da política industrial a partir do trabalho das instituições designadas pelo governo federal (ALMEIDA, 2009).

Mas isso não isentou a PDP de grandes críticas em relação a uma característica 
sua, a chamada política para "escolha de vencedores". Assim, a PDP teria contribuído para que órgãos do governo federal, como o Banco Nacional de Desenvolvimento Econômico e Social (BNDES), atuassem em prol de concessões e políticas favoráveis à expansão de grandes conglomerados produtivos nacionais, elegidos com potencial para se tornarem grandes empresas brasileiras, com maior competitividade no cenário internacional (ALMEIDA, 2009).

Por fim, completando o pacote de três grandes planos de política industrial do governo federal brasileiro pós-2003, em agosto de 2011 a presidente Dilma Rousseff lançou o Plano Brasil Maior (PBM). O slogan do programa era "Inovar para competir. Competir para crescer" e uma das principais características da política estava na desoneração tributária orçada em $\mathrm{R} \$ 25$ bilhões, num período de dois anos. Além disso, a política determinou que setores sensíveis a variações cambiais e à concorrência cambial (tal como calçados, confecções, móveis e software) teriam a sua alíquota de recolhimento ao INSS zerada (ABDI, 2014).

O PBM também seguiu a orientação de um plano de política industrial direcionado por medidas setoriais, a partir das quais 19 setores foram selecionados para receber estímulos. Mattos (2013) aponta que foram 287 medidas disponibilizadas para atender àqueles setores, dentre as quais cerca de $1 / 4$ são direcionadas para a agroindústria. Isso caracterizaria a política como tendo um perfil seguidor das demandas de setores que já se demonstravam mais relevantes acerca da competitividade industrial que dispunham perante outros segmentos.

Mattos (2013) faz uma análise crítica do PBM ao considerar que há um claro viés protecionista da política, porque ela inclui a concessão de margens de preferência em licitações, exigência de conteúdo nacional e variações de tarifas, de modo a discriminar produtos importados. E, ainda que o plano mencionasse metas quantitativas, não havia registros claros sobre como funcionariam os canais de transmissão e mensuração de resultados. Isso atestaria que o PBM seria a continuidade do perfil da política industrial realizada no Brasil anteriormente, sem novidades reais (MATTOS, 2013).

O uso de políticas industriais no contexto recente passou a ser visto como um instrumento necessário para o alcance do desenvolvimento econômico e social no Brasil. Contudo, ainda há desafios estruturais que persistem, de modo a transformar 
a política industrial em um instrumento de ação permanente e não viesado a favor de interesses privados de curto prazo, em detrimento ao amplo desenvolvimento de longo prazo do país.

\section{CONSIDERAÇÕES FINAIS}

Discutir o desenvolvimento econômico refere-se a uma tentativa de se planejar e discutir o futuro de longo prazo. Diferentemente do que ocorre no debate econômico sobre perspectivas de ajustes macroeconômicos (de curto prazo), pensar-se o desenvolvimento exige o desenho de ações por parte do Estado. Esse tipo de comportamento pode se restringir ao papel do Estado no que se refere, somente, a garantir que os agentes privados tenham liberdade de ação e cenários propícios para a continuidade e expansão de suas ações, com vistas à acumulação privada do capital.

No entanto, o Estado pode se utilizar de outros mecanismos para que em determinados contextos específicos, haja condições de se estimular os capitais privados a atuarem em direções que são consideradas relevantes e estratégicas para o desenvolvimento de longo prazo de uma nação. Nesse sentido que se justifica a ação de Policy makers quando do desenho e aplicação de políticas públicas com vistas à intervenção do Estado em cenários, em tese, caracteristicamente privados.

$\mathrm{Na}$ América Latina esse tipo de situação oscilou fortemente ao longo da segunda metade do século $\mathrm{XX}$, pois as concepções ideológicas em diferentes momentos do tempo fizeram com que as posturas defendidas se alternassem entre momentos em que o Estado era o promotor do desenvolvimento e outros em que ele não possuía 'legitimidade' (por parte do capital financeiro) para intervir e estimular ações que pudessem vislumbrar melhores resultados econômicos, e consequentemente, sociais.

Assim, esse artigo teve o interesse de apresentar algumas ideias, no que se refere ao papel do Estado, quando da sua intervenção na economia por meio de políticas públicas, ou ainda, industriais, e que têm o objetivo de estimular uma dinâmica produtiva e tecnológica em segmentos ou áreas que são consideradas 
importantes para o avanço de uma nação. Ao se resgatar alguns momentos da história, pode-se perceber que esse tipo de comportamento do Estado não é uma novidade, pois os países que hoje são considerados desenvolvidos se utilizaram pesadamente de políticas intervencionistas em prol de seu desenvolvimento.

\section{REFERÊNCIAS}

ABDI. Agência Brasileira de Desenvolvimento Industrial (ABDI). Relatório de Macrometas: Política de Desenvolvimento Produtivo (Maio/2008 - Julho/2009). Brasília, DF: Ministério da Fazenda, 2008.

ABDI. Agência Brasileira de Desenvolvimento Industrial (ABDI). Balanço Executivo 2011-2014 do Plano Brasil Maior. Brasília, 2014. Disponível em: < http://www. abdi.com.br/Estudo/Relatorio\%20PBM\%202011-2014.pdf>. Acesso em: 15 mar. 2017.

ALMEIDA, M. Desafios da real política industrial brasileira do século XXI. Brasília: IPEA, 2009. (Texto para Discussão N. 1452).

BOYER, R. Estado, Mercado e Desenvolvimento: uma nova síntese para o século XXI. In Economia e Sociedade, Campinas, v. 12, p. 1-20, jun. 1999.

BRASIL. Política Industrial, Tecnológica e de Comércio Exterior. 2003. Disponível em: < http://www.abdi.com.br/Estudo/Diretrizes_PITCE.pdf>. Acesso em: 15 mar. 2017.

BRASIL. Lei No 10.973, de 2 de dezembro de 2004. "Lei da Inovação Tecnológica". 2004. Disponível em: < http://www.planalto.gov.br/ccivil_03/_ato2004-2006/2004/ lei/110.973.htm > . Acesso em: 15 mar. 2017.

BRASIL. Lei No 11.196 de 21 de novembro de 2005. "Lei do Bem”. 2005. Disponível em: <http://www.planalto.gov.br/ccivil_03/_ato2004-2006/2005/lei/111196.htm>. 
Acesso em: 15 mar. 2017.

BRESSER-PEREIRA, L. C. Estado, Sociedade civil e Legitimidade democrática. Lua Nova [online], n. 36, p. 85-104, 1995.

CHANG, H. J. Chutando a Escada: a estratégia do desenvolvimento em perspectiva histórica. São Paulo: Ed. UNESP, 2004.

CHESNAIS, F. A Mundialização do capital. São Paulo: Xamã, 1996.

FERRAZ, M. Retomando o debate: a nova política industrial do Governo Lula. Planejamento e Políticas Públicas - PPP., n. 32, jan./jun. 2009.

FORGIONI, P. Análise Econômica do Direito: paranoia ou mistificação? In: COUTINHO, J.; LIMA, M. Diálogos Constitucionais: direito neoliberalismo e desenvolvimento em países periféricos. Rio de Janeiro: Renovar, 2005.

MATTOS, C. Análise do Plano Brasil Maior. Consultoria Legislativa da Câmara dos Deputados. Brasília, 2013.

MOREIRA, E. O Direito Administrativo contemporâneo e a Intervenção do Estado na ordem econômica. In Revista Eletrônica de Direito Administrativo Econômico, Salvador, n. 1, fev./abr. 2005.

MOREIRA NETO, D. F. O Novo papel do Estado na Economia. Revista de Direito Público da Economia - RDPE, Belo Horizonte, v. 1, n.1 jan./mar 2003.

POLANYI, K. A Grande transformação: as origens de nossa época. Tradução de Fanny Wrabel. 2. ed. Rio de Janeiro: Campus, 2000.

PREBISCH, R. O Desenvolvimento Econômico da América Latina e alguns de seus principais problemas. In: BIELSCHOWSKY, R. (Org). Cinquenta anos de 
pensamento na CEPAL. Rio de Janeiro: Record, 2000.

REINERT, E. Catching-up from way behind: a third world perspective on first world history. Mimeo. 1994. Disponível em: < http:/www.othercanon.org/papers/ index.html> . Acesso em: 15 mar. 2017.

REINERT, E. Diminishing Returns and Economic Sustainability: the dilemma of resource-based economies under a free trade regime. Mimeo. 1996. Disponível em: < http://www.othercanon.org/papers/index.html > . Acesso em: 15 mar. 2017.

SMITH, M. R. Technological Determinism in American culture. MARX, L.; SMITH, M. R. (Ed.). The Dilemma of Technological Determinism. Cambridge, Mass: MIT Press, 1996.

STRECK, L.; MORAIS, J. L. B. A Peculiaridade do Intervencionismo do Estado no Brasil: a crônica de um simulacro e a crise da modernidade. In: CIÊNCIA Política e Teoria Geral do Estado. 2. ed. rev. e ampl. Porto Alegre: Livraria do Advogado, 2001.

SUZIGAN, W.; FURTADO, J. Política Industrial e Desenvolvimento. Revista de Economia Política, v. 26, n. 2 (102), p. 163-185, abr.jun. 2006.

SUZIGAN, W.; ALBUQUERQUE, E. A Interação entre Universidades e Empresas em perspectiva histórica no Brasil. In: SUZIGAN, W.; ALBUQUERQUE, E.; CARIO, S. (Org.). Em busca da Inovação: interação universidade-empresa no Brasil. Belo Horizonte: Autêntica, 2011.

VERÍSSIMO, M.; MIRANDA, G.; MIRANDA, A. Ajuste Neoliberal e a crise do Estado: necessidade de se retomar a autonomia dos Estados Nacionais. In: SIMPÓSIO INTERNACIONAL "O ESTADO E AS POLÍTICAS EDUCACIONAIS NO TEMPO PRESENTE", 5., Anais... Uberlândia: Universidade Federal de Uberlândia, 2009. Disponível em: <http://www.simposioestadopoliticas.ufu.br/imagens/anais/pdf/ AC04.pdf>. Acesso em: 15 mar. 2017. 